\title{
Glycemic index of a meal fed before exercise alters substrate use and glucose flux in exercising horses
}

\author{
EDUARD JOSE-CUNILLERAS, ${ }^{1}$ KENNETH W. HINCHCLIFF, ${ }^{1}$ RICHARD A. SAMS, ${ }^{1}$ \\ STEVEN T. DEVOR, ${ }^{2}$ AND JON K. LINDERMAN ${ }^{3}$ \\ ${ }^{1}$ Department of Veterinary Clinical Sciences, College of Veterinary Medicine and ${ }^{2}$ Section of Sport \\ and Exercise Sciences, The Ohio State University, Columbus 43210; and ${ }^{3}$ Department of \\ Health and Sport Science, School of Education and Allied Professions, \\ University of Dayton, Dayton, Ohio 45469
}

Received 17 May 2001; accepted in final form 6 September 2001

\begin{abstract}
Jose-Cunilleras, Eduard, Kenneth W. Hinchcliff, Richard A. Sams, Steven T. Devor, and Jon K. Linderman. Glycemic index of a meal fed before exercise alters substrate use and glucose flux in exercising horses. J Appl Physiol 92: 117-128, 2002.-In a randomized, balanced, crossover study each of six fit, adult horses ran on a treadmill at $50 \%$ of maximal rate of oxygen consumption for $60 \mathrm{~min}$ after being denied access to food for $18 \mathrm{~h}$ and then 1 ) fed corn (51.4 kJ/kg digestible energy), or 2) fed an isocaloric amount of alfalfa $2-3 \mathrm{~h}$ before exercise, or 3 ) not fed before exercise. Feeding corn, compared with fasting, resulted in higher plasma glucose and serum insulin and lower serum nonesterified fatty acid concentrations before exercise $(P<0.05)$ and in lower plasma glucose, serum glycerol, and serum nonesterified fatty acid concentrations and higher skeletal muscle utilization of blood-borne glucose during exercise $(P<$ 0.05). Feeding corn, compared with feeding alfalfa, resulted in higher carbohydrate oxidation and lower lipid oxidation during exercise $(P<0.05)$. Feeding a soluble carbohydraterich meal (corn) to horses before exercise results in increased muscle utilization of blood-borne glucose and carbohydrate oxidation and in decreased lipid oxidation compared with a meal of insoluble carbohydrate (alfalfa) or not feeding. Carbohydrate feedings did not produce a sparing of muscle glycogen compared with fasting.
\end{abstract}

glycogen; corn; alfalfa

MUSCLE GLYCOGEN AND blood-borne glucose are important substrates for contracting skeletal muscle during moderate-intensity exercise bouts. Carbohydrate (CHO) metabolism in exercising muscle and the factors that influence $\mathrm{CHO}$ metabolism during exercise in horses are assumed to be similar to humans. However, this may not necessarily be the case. Horses have a greater aerobic capacity than humans, and, therefore, at the same exercise intensity relative to the maximal rate of oxygen consumption $\left(\dot{\mathrm{V}}_{2}\right.$ max $)$, the rate of oxygen consumption $\left(\dot{\mathrm{V}}_{2}\right)$ and the energy expenditure are much higher in horses than in humans (46). In addition to the greater aerobic capacity of horses, the anatomy and physiology of their gastrointestinal tract is adapted

Address for reprint requests and other correspondence: K. W. Hinchcliff, College of Veterinary Medicine, 601 Vernon L. Tharp St., Columbus, OH 43210 (E-mail: hinchcliff.2@osu.edu). to a herbivorous diet based on ingestion of structural CHOs of plants (mainly cellulose and hemicellulose) and bacterial fermentation of structural CHOs in the hindgut with subsequent absorption of volatile fatty acids (VFAs; acetate, propionate, and butyrate). Horses obtain a substantial proportion of their energy requirements from absorption of VFAs during resting conditions as well as during low-intensity exercise; however, the contribution of VFAs to energy expenditure during exercise is unknown. Thereby, the observations made in human subjects regarding $\mathrm{CHO}$ metabolism in exercising skeletal muscle and the influence of nutritional status on CHO metabolism may not apply to horses because of the aforementioned physiological differences between horses and humans.

Among the numerous factors that influence $\mathrm{CHO}$ metabolism in exercising muscle, there is evidence, in studies in human subjects, that diet composition and interval before exercise can affect both uptake of glucose by muscle and the rate of muscle glycogen utilization. In studies performed in human subjects, ingestion of glucose or a high-glycemic meal (HGM) before exercise results in enhanced $\mathrm{CHO}$ oxidation $\left(\mathrm{CHO}_{\text {ox }}\right)$ and utilization of blood-borne glucose, and the rate of glycogenolysis is enhanced (18) or unchanged $(8,17,22$, 23). In humans, ingestion of a HGM or CHO supplementation before and/or during endurance and moderate-intensity exercise has resulted in enhanced $(1,2,4$, $5,13,16,23,37,38,45,49$ ), decreased (44), or unchanged submaximal exercise performance $(8,9,18$, $40,47)$. Current recommendations of feeding before and during endurance exercise in human athletes include ingestion of $\mathrm{CHO}$ solutions to maintain the rate of $\mathrm{CHO}_{\text {ox }}$ (21).

Studies performed in horses have determined the effect of meal composition and interval before exercise on the blood concentrations of substrates and hormones and muscle glycogen utilization during exercise $(7,24,25,29,30,34,43)$; however, the relative contributions of $\mathrm{CHO}_{\mathrm{ox}}$, in the form of blood-borne glucose

The costs of publication of this article were defrayed in part by the payment of page charges. The article must therefore be hereby marked "advertisement" in accordance with 18 U.S.C. Section 1734 solely to indicate this fact. 
and muscle glycogen utilization, and lipid oxidation to energy production during exercise have not been determined. In brief, ingestion of a HGM $2-4 \mathrm{~h}$ before a moderate-intensity exercise bout results in a transient decrease in plasma glucose concentration during exercise, attenuation of exercise-induced increase of nonesterified fatty acid (NEFA) concentration, and increased serum insulin concentration during exercise compared with horses withheld from food or fed a hay meal. These alterations in plasma and serum concentrations of substrates and hormones have been hypothesized to be deleterious for performance in horses, presumably because of impaired substrate use during exercise. However, none of these studies has determined the effect of meal composition before exercise on substrate use during exercise or on measurements of exercise performance in horses.

If similar mechanisms regulate $\mathrm{CHO}$ metabolism in working skeletal muscle in horses and in humans, it is plausible that preexercise ingestion of a HGM in horses may enhance glucose availability to skeletal muscle and alter the hormonal milieu so that $\mathrm{CHO}_{\text {ox }}$ is maintained and lipid oxidation is suppressed, compared with ingestion of a low-glycemic meal (LGM) or not feeding before exercise. To date, however, this hypothesis has not been tested. The present study was, therefore, undertaken to determine the effects of glucose supply [preexercise ingestion of a HGM (corn) vs. preexercise ingestion of a LGM (hay) vs. withholding feed] on stable isotope tracer-determined whole body glucose appearance and uptake in horses during moderate-intensity exercise. It was hypothesized that ingestion of a HGM before exercise would result in enhanced whole body glucose appearance and uptake. A further objective of this study was to determine the effects of glucose supply on whole body rates of $\mathrm{CHO}_{\mathrm{ox}}$ and lipid oxidation and relative contribution of these fuels to energy expenditure as well as to the rate of muscle glycogenolysis. It was hypothesized that ingestion of a HGM before exercise would result in enhanced $\mathrm{CHO}_{\text {ox }}$, attenuated lipid oxidation, greater relative contributions to energy expenditure from blood-borne glucose, and attenuated muscle glycogenolysis ("muscle glycogen-sparing effect").

\section{MATERIALS AND METHODS}

All animal experiments were conducted after approval by the Institutional Laboratory Animal Care and Use Committee of The Ohio State University and were performed in compliance with their guidelines and recommendations.

Experimental design. The effects of feeding a meal of corn or alfalfa before exercise on glucose kinetics, whole body substrate utilization, and muscle glycogen utilization during moderate-intensity exercise were examined in a balanced, randomized, three-way crossover study. Six horses undertook $60 \mathrm{~min}$ of treadmill exercise at a workload requiring $50 \%$ $\mathrm{V}_{2}$ max in each of three experimental conditions: 1) $90 \mathrm{~min}$ after consuming a meal of cracked corn $[1.7 \mathrm{~kg}$ in a $450 \mathrm{-kg}$ horse; $12.4 \mathrm{kcal} / \mathrm{kg}(51.8 \mathrm{~kJ} / \mathrm{kg})$ digestible energy; grain trial]; 2) 90 min after consuming a meal of an isocaloric amount of alfalfa cubes ( $3.0 \mathrm{~kg}$ in a $450-\mathrm{kg}$ horse; hay trial); and 3) after having feed withheld for $18 \mathrm{~h}$ (feed-withholding trial). In preliminary studies, it was determined that horses offered hay were not able to consume the entire meal in $60 \mathrm{~min}$. For this reason, horses were allowed to eat the grain meal from 0800 to $0900(60 \mathrm{~min})$ and the hay meal from 0700 to 0900 (120 min). Trials were separated by 7 days, and the order of the trials was randomized for individual horses but balanced among treatments.

Horses. Six Standardbred horses (5 mares and 1 gelding), $4-11 \mathrm{yr}[7.8 \pm 2.5(\mathrm{SD}) \mathrm{yr}]$ of age and $404-485 \mathrm{~kg}[425 \pm 30$ (SD) $\mathrm{kg}]$ body mass, were studied. All horses were housed indoors during the experimental period, fed a diet of timothy grass-alfalfa hay, alfalfa cubes, mixed pelleted grain, and cracked corn, and had unlimited access to a salt-mineral block and water. All horses were conditioned and undertaking regular treadmill exercise for 6 wk before the study. Horses were not exercised the day before an experimental trial, and, after an experimental trial, they received 4 days of light treadmill exercise (30 min of trotting at $4-4.5 \mathrm{~m} / \mathrm{s}$ with the treadmill set at $4^{\circ}$ incline).

Preliminary testing. For each horse, $\dot{\mathrm{V}}_{2}$ max and the relationship between rate of $\mathrm{V}_{2}$ and speed were determined during an incremental exercise test $1 \mathrm{wk}$ before the first experiment. The incremental exercise test consisted of the horse running on a high-speed treadmill (Sato, Uppsala, Sweden) inclined at $4^{\circ}$ for $90 \mathrm{~s}$ at $4 \mathrm{~m} / \mathrm{s}$; the treadmill speed was then increased by $1 \mathrm{~m} / \mathrm{s}$ every $90 \mathrm{~s}$ until the horse was no longer able to maintain its position on the treadmill. $\dot{\mathrm{V}}_{\mathrm{O}_{2}}$ was measured every $10 \mathrm{~s}$ during the exercise test. $\mathrm{V}_{2}$ max was defined as the value at which $\mathrm{V}_{2}$ reached a plateau, despite further increases in speed. A plateau was defined as a change in $\mathrm{VO}_{2}$ of $<4 \mathrm{ml} \cdot \mathrm{kg}^{-1} \cdot \mathrm{min}^{-1}$ with an increase in speed. The running speed that elicited $50 \% \dot{\mathrm{V}}_{2}$ max was calculated for each horse using linear regression analysis of speeds below $\dot{\mathrm{V}}_{2}$ max.

Diet composition. Horses were fed a basal diet of mixed alfalfa and grass hay and pelleted concentrate to maintain ideal body weight (condition score 5-6 out of 9). Corn and alfalfa cubes were fed beginning $4 \mathrm{wk}$ before the start of the experimental trials so that horses were accustomed to the diet. The diet consisted of $4.8 \mathrm{~kg}$ of alfalfa hay cubes, $2.9 \mathrm{~kg}$ of mixed hay, $1.4 \mathrm{~kg}$ of pelleted concentrate, and $1 \mathrm{~kg}$ of cracked corn per day for a 450-kg horse. The amounts of hay and grain were given following the guidelines published by the National Research Council for horses in moderate work (28). The equation used for estimation of daily requirements of digestible energy (Mcal of DE/day) was

$$
\mathrm{DE}=1.5 \cdot(1.4+0.03 \cdot \mathrm{BW})
$$

where $\mathrm{DE}$ is the daily requirement of digestible energy (Mcal/ day) and BW is the body weight $(\mathrm{kg})$. The roughage and concentrates in the diet were analyzed by a commercial laboratory (Holmes Laboratory, Millersburg, $\mathrm{OH}$ ) (Table 1).

Experimental protocol. Before each experimental trial, food was withheld for $18 \mathrm{~h}$, and the horses were confined to their stalls for $24 \mathrm{~h}$. All experiments began at 0700 when horses were offered alfalfa cubes or at 0800 when horses were offered cracked corn. After aseptic preparation and injection of local anesthesia of the overlying skin, catheters (14 gauge, 5.25 in.; Angiocath, Becton Dickinson) were inserted into the right and left jugular veins for isotope infusion and blood sample collection, respectively. Thereafter, a blood sample was obtained for subsequent determination of background isotopic enrichment. In the grain trial, horses were fed, at 0800 in their stall, a meal of cracked corn corresponding to one-quarter of the daily energy requirements as previously established for horses on moderate work (28). In the hay trial, horses were fed, at 0700 in their stall, an isocaloric meal 
Table 1. Result of analysis of the dietary components

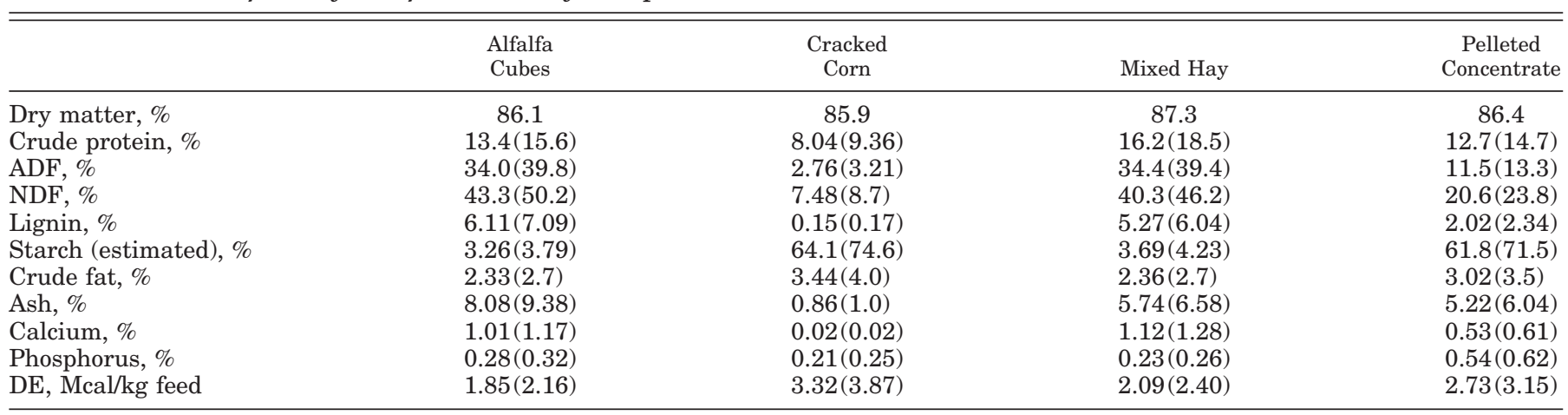

Values are as sampled and, in parentheses, as a dry matter basis. ADF, acid detergent fiber; NDF, neutral detergent fiber; DE, digestible energy.

of alfalfa cubes. In the feed-withholding trial, horses were not fed before exercise. In all trials, horses were kept undisturbed (with the exception of blood sampling from the jugular catheter) in the stall until 0900 . Horses were then moved to stockades in a temperature-controlled building. Glucose kinetics was determined by a primed $(17.5 \mu \mathrm{mol} / \mathrm{kg})$, continuous $\left(0.22 \pm 0.01 \mu \mathrm{mol} \cdot \mathrm{kg}^{-1} \cdot \mathrm{min}^{-1}\right)$ infusion of $\left[6,6-^{2} \mathrm{H}\right] \mathrm{glu}-$ cose (99\% enriched; Cambridge Isotopes, Cambridge, MA) in $0.9 \%$ saline. The $\left[6,6{ }^{2} \mathrm{H}\right]$ glucose was infused for 90 min with a calibrated infusion pump while the horses stood quietly in the stocks. Fifteen minutes before initiation of exercise, a sample of the middle gluteal muscle was obtained by percutaneous biopsy. Thereafter, the horses were positioned on an inclined treadmill ( $4^{\circ}$ incline), and a loose-fitting face mask for measurement of respiratory gas exchange was applied. The horses completed a 5 -min warm-up $(3 \mathrm{~m} / \mathrm{s}$ treadmill belt speed) followed by 60 min of running at a speed calculated to elicit $50 \% \dot{\mathrm{V}}_{2}$ max. The rate of $\left[6,6{ }^{2} \mathrm{H}\right]$ glucose infusion was tripled $\left(0.66 \pm 0.02 \mu \mathrm{mol} \cdot \mathrm{kg}^{-1} \cdot \mathrm{min}^{-1}\right)$ during the warm-up. During the exercise test, fans mounted $0.5 \mathrm{~m}$ in front and to the sides of the treadmill were used to maintain an air velocity of $\sim 4 \mathrm{~m} / \mathrm{s}$ over the horse. Ambient conditions were similar for all trials (room temperature and relative humidity were $15-20^{\circ} \mathrm{C}$ and $50-60 \%$, respectively).

Respiratory exchange measurements. $\dot{\mathrm{V}}_{2}$, carbon dioxide production $\left(\dot{\mathrm{V}}_{2}\right)$, and respiratory exchange ratio (RER) were measured with an open-circuit calorimeter (Oxymax$\mathrm{XL}$, Columbus Instruments, Columbus, OH) as previously described (19). Flow through the system was $\sim 1,500 \mathrm{l} / \mathrm{min}$ STP when the horse was stationary and 9,000 1/min during running. Data for expired $\mathrm{O}_{2}$ (electrochemical cell, Columbus Instruments) and $\mathrm{CO}_{2}$ (single-beam nondispersive infrared sensor, Columbus Instruments) concentrations were measured continuously and were reported at $10-$ s intervals. The gas-analysis system was calibrated before the start of each exercise test by using gas mixtures with oxygen and carbon dioxide concentrations that spanned the measurement range. The overall accuracy of the system for the measurement of $\dot{\mathrm{V}}_{2}$ was verified for each run by the nitrogen-dilution method, and measured values were corrected for any discrepancy (10). The accuracy of the system for the measurement of RER was verified for each run by burning of propane, which has a respiratory quotient of 0.6 , and measured values were corrected for any discrepancy. Standard equations were used to calculate $\dot{\mathrm{V}}_{2}$ and $\dot{\mathrm{V}}_{2}$, and $\mathrm{RER}$ was obtained by dividing $\dot{\mathrm{V}} \mathrm{CO}_{2}$ by $\dot{\mathrm{V}}_{2}$.

Sampling procedures. Blood samples were obtained at -60 and -30 min for hay trials and at $0,30,60,90,120,135,150$,
$155,165,180,195$, and $210 \mathrm{~min}$ for all trials (where the "0"-min sample was collected at 0800 when the first sample was obtained in grain and feed-withholding trials). Blood samples were divided (6-ml aliquots) into four different tubes for subsequent analysis. Two aliquots of each sample were placed in evacuated tubes containing EDTA. These samples were later analyzed for plasma isotopic enrichment, hematocrit, plasma total protein, NEFA, and glycerol concentrations. A $6-\mathrm{ml}$ aliquot was placed in a tube containing sodium fluoride-potassium oxalate for subsequent determination of plasma glucose and lactate concentration. The final aliquot was placed in a tube containing no additive for measurement of serum immunoreactive insulin (IRI) concentration. Plasma or serum was obtained by centrifugation $(1,500 \mathrm{~g}$ for $20 \mathrm{~min}$ at $4^{\circ} \mathrm{C}$ ) within $30 \mathrm{~min}$ of collection and frozen at $-80^{\circ} \mathrm{C}$ until analysis.

Muscle biopsy samples were collected percutaneously from the middle gluteal muscle via the needle-biopsy technique (26). Muscle biopsies were obtained $15 \mathrm{~min}$ before commencement of exercise and within $3 \mathrm{~min}$ of cessation of exercise. Muscle samples were immediately placed in liquid nitrogen and stored at $-80^{\circ} \mathrm{C}$ until analysis.

Plasma isotopic enrichment. Plasma $\left[6,6{ }^{2} \mathrm{H}\right]$ glucose enrichment was determined as previously described and performed by our laboratory (14). The intra- and interassay coefficients of variation were $1.6 \pm 0.1$ and $2.7 \pm 0.4$, respectively. To control for between-day variability in plasma $[6,6$ $\left.{ }^{2} \mathrm{H}\right]$ glucose enrichment determination, all samples for a given horse (feed-withholding, hay, and grain trials) were analyzed during the same analytic session. All samples were analyzed in duplicate.

Plasma biochemical analyses. Plasma glucose concentration was measured spectrophotometrically using a commercial kit that employs the hexokinase reaction (glucose hexokinase kit, Sigma Diagnostics, St. Louis, MO), and plasma lactate concentration was measured by using an automated lactate oxidase method (Sport 1500 lactate analyzer, Yellow Springs Instruments, Yellow Springs, OH). Plasma NEFA concentration was determined by using a commercial kit that employs an enzymatic colorimetric method (NEFA test kit, Wako Chemicals, Dallas, TX). Plasma glycerol concentration was measured by using an enzymatic spectrophotometric method [triglycerides kit 337A (without triglyceride hydrolysis step), Sigma Diagnostics]. Plasma glucose, NEFA, and glycerol concentrations were measured by using a microplate reader spectrophotometer (Versamax, Molecular Devices, Sunnyvale, CA). Intra- and interassay coefficients of variation for measurement of plasma glucose, lactate, NEFA, and 
glycerol were $\sim 1.0$ and $\sim 2.5 \%$, respectively. Hematocrit was measured by the microhematocrit technique. Plasma total protein was measured by refractometry (Cambridge Instruments, Buffalo, NY). To control for between-day variability, all samples for a given horse (feed-withholding, hay, and grain trials) were analyzed during the same analytic session. All samples were analyzed in duplicate.

Plasma hormone analyses. Serum IRI was determined in duplicate by use of a commercially available RIA (insulin kit, Coat-a-Count Diagnostics, Los Angeles, CA) that has been validated for horse blood (33). Intra- and interassay coefficients of variation were $\sim 6$ and $\sim 8 \%$.

Muscle glycogen. Muscle samples were dissected free of any blood and connective tissue, and duplicate samples, of 20 $\mathrm{mg}$ each, were analyzed. The samples were extracted and analyzed for muscle glycogen concentration (as glucosyl units per $\mathrm{kg}$ of wet weight) according to the procedure of Passonneau and Lauderdale (32). Bovine liver glycogen (G0885, Sigma Diagnostics) was used to obtain known standard concentrations of 200 and $50 \mathrm{mM}$, as a quality control for the acid hydrolysis procedure. Intra- and interassay coefficients of variation were 9.4 and $12.3 \%$, respectively.

Calculations of glucose kinetics. Glucose rate of appearance $\left(R_{a}\right)$ and rate of disappearance $\left(R_{d}\right)$ at rest were calculated by using the steady-state tracer dilution equation (48)

$$
\mathrm{R}_{\mathrm{a}}=\mathrm{R}_{\mathrm{d}}=\mathrm{F} \cdot\left[\left(\mathrm{IE}_{\mathrm{i}} / \mathrm{IE}_{\mathrm{p}}\right)-1\right]
$$

where $\mathrm{F}$ is the infusion rate of the isotope $\left(\mu \mathrm{mol} \cdot \mathrm{kg}^{-1}\right.$. $\left.\min ^{-1}\right) ; \mathrm{IE}_{\mathrm{i}}$ and $\mathrm{IE}_{\mathrm{p}}$ are the stable isotopic enrichment of the infusate and plasma, respectively; and - 1 accounts for the tracer's contribution to the turnover rate of the substrate (48). The rate of infusion was calculated by multiplying the infusion pump rate by the concentration of glucose in the infusate. During exercise, glucose $R_{a}$ and $R_{d}$ were calculated by using the non-steady-state equation developed by Steele (41) and modified for use with stable isotopes. This equation is modified for use with stable isotopes as the amount of tracer infused is no longer negligible

$$
\mathrm{R}_{\mathrm{a}}=\frac{\mathrm{F}-\mathrm{V}_{\mathrm{d}} \frac{\mathrm{C}_{\mathrm{m}}}{1+\mathrm{E}} \frac{\mathrm{dE}}{\mathrm{d} t}}{\mathrm{E}}
$$

and

$$
\mathrm{R}_{\mathrm{d}}=\mathrm{R}_{\mathrm{a}}-\mathrm{V}_{\mathrm{d}} \frac{\frac{\mathrm{dC}_{\mathrm{m}}}{\mathrm{d} t}(1+\mathrm{E})-\mathrm{C}_{\mathrm{m}} \frac{\mathrm{dE}}{\mathrm{d} t}}{(1+\mathrm{E})^{2}}
$$

where $\mathrm{V}_{\mathrm{d}}$ is the effective volume of distribution, $\mathrm{E}$ is the plasma isotopic enrichment, $\mathrm{C}_{\mathrm{m}}$ is the measured plasma concentration of the tracee, and $\mathrm{dE} / \mathrm{d} t$ and $\mathrm{dC}_{\mathrm{m}} / \mathrm{d} t$ are maximum rates of change in enrichment and glucose concentration, respectively, as a function of time. With use of this fixed, one-compartment model of Steele, it is assumed that 1) the apparent glucose space is $25 \%$ of body weight and 2) $65 \%$ of this space represents the rapidly mixing portion of the glucose pool. Therefore, the effective $V_{d}$ for glucose was assumed to be $162 \mathrm{ml} / \mathrm{kg}$. Glucose metabolic clearance rate (MCR) was calculated by dividing glucose $R_{d}$ by the plasma glucose concentration. Glucose $\mathrm{R}_{\mathrm{a}}$ was assumed to represent glucose absorption from the gastrointestinal tract plus hepatic glucose production, although a small contribution from renal glycogenolysis and gluconeogenesis is possible.

Rates of energy expenditure and whole body substrate oxidation. Total energy expenditure (TEE) and absolute rates of $\mathrm{CHO}_{\text {ox }}$ and lipid oxidation were calculated as follows $(11,12)$

$$
\begin{gathered}
\mathrm{TEE}(\mathrm{kcal} / \mathrm{min})=3.9 \dot{\mathrm{VO}}_{2}+1.1 \dot{\mathrm{V}}_{\mathrm{CO}_{2}} \\
\mathrm{CHO}_{\mathrm{ox}}(\mathrm{g} / \mathrm{min})=4.585 \dot{\mathrm{V}}_{\mathrm{CO}_{2}}-3.2255 \dot{\mathrm{V}}_{2} \\
\text { Lipid oxidation }(\mathrm{g} / \mathrm{min})=1.7012 \dot{\mathrm{V}}_{2}-1.694 \dot{\mathrm{V}}_{\mathrm{CO}_{2}}
\end{gathered}
$$

where $\dot{\mathrm{V}}_{2}$ is in liters per minute and it was assumed that protein oxidation made a negligible contribution to $\dot{\mathrm{V}}_{2}$ and $\mathrm{VCO}_{2}$ (i.e., nonprotein RER). The calculated values were based on respiratory gas exchange values averaged over 5 -min intervals. $\mathrm{CHO}_{\text {ox }}$ in grams per minute was converted to micromoles per kilogram per minute by dividing by the molecular weight of glucose (mol wt 180.16) and the horse's body weight. Similarly, rates of fat oxidation were converted to micromoles per kilogram per minute by dividing by the molecular weight of palmitate (mol wt 256.43) and the horse's body weight. Muscle glycogen (plus lactate) oxidation was calculated as the difference between total $\mathrm{CHO}_{\text {ox }}$ and glucose $R_{\mathrm{d}}$. Coggan et al. (3) reported that, in human subjects, $>95 \%$ of glucose $R_{d}$ is oxidized during submaximal exercise. Therefore, glucose $R_{d}$ provides a reasonable estimate of plasma glucose oxidation during exercise. Finally, the absolute and relative contributions by plasma glucose, other CHO sources (muscle glycogen and lactate), and lipid to the TEE during the 0 - to 30 - and the 35- to 60 -min periods of exercise were estimated using standard caloric equivalents (4.2 kcal/g CHO, $9.0 \mathrm{kcal} / \mathrm{g}$ lipid).

Statistical analyses. Values are means $\pm \mathrm{SE}$. The data for all dependent measures were analyzed using a two-way ANOVA for repeated measures, with treatment (feed withholding, hay, and grain) and time as independent factors. Percent data were subject to arcsine transformation before ANOVA. The null hypothesis was rejected at $\alpha \leq 0.05$ for the main effects (treatment and time) and $\alpha \leq 0.10$ for the interaction. Significant differences identified by ANOVA were isolated using the Tukey post hoc test. The only dependent variable analyzed with a paired Student's $t$-test was the difference in the relative feed consumptions between hay and grain meals. The Sigmastat 2.0 software package (Jandel Scientific, San Rafael, CA) was used for statistical computations.

\section{RESULTS}

Individual values for $\dot{\mathrm{V}}_{2}$ max ranged from 109 to 125 $\mathrm{ml} \cdot \mathrm{kg}^{-1} \cdot \mathrm{min}^{-1}$ (mean $117 \pm 2.7 \mathrm{ml} \cdot \mathrm{kg}^{-1} \cdot \mathrm{min}^{-1}$ ). Mean running speed on a $4^{\circ}$ inclined treadmill during the exercise protocol was $4.9 \pm 0.2 \mathrm{~m} / \mathrm{s}$ (range $4.3-5.5$ $\mathrm{m} / \mathrm{s}$ ), which corresponded to a relative workload of $50 \pm$ $0.7 \%$ of $\dot{\mathrm{V}}_{2}$ max (range $46.9-52.4 \%$ ).

Preexercise feed consumption. Before exercise in hay meal trials, horses were offered $2.9 \pm 0.1 \mathrm{~kg}(6.3 \pm 0.2$ lb.; range $2.7-3.3 \mathrm{~kg}$ ) and consumed $82 \pm 8 \%$ (range 64-100\%) of the meal. In grain meal trials, horses were offered $1.6 \pm 0.04 \mathrm{~kg}(3.5 \pm 0.1 \mathrm{lb}$.; range $1.5-1.8 \mathrm{~kg})$ and all horses consumed all of the meal. The difference in caloric intake between the two meals was $\sim 10 \pm 3.9$ $\mathrm{kJ} \mathrm{DE} / \mathrm{kg}$ of body weight $(2.4 \pm 0.9 \mathrm{kcal} / \mathrm{kg}$ ) (range $0-19 \mathrm{~kJ} / \mathrm{kg}$ ). The meal consumption in hay trials had a tendency to be lower than in grain trials $(P=0.06)$.

Plasma glucose concentration. Feeding type before exercise significantly affected plasma glucose concentrations before and during exercise. Before ingestion of a meal, plasma glucose was similar among the three trials (Fig. 1A). During the 150-min period, after the horses were allowed to eat a grain meal equivalent to 

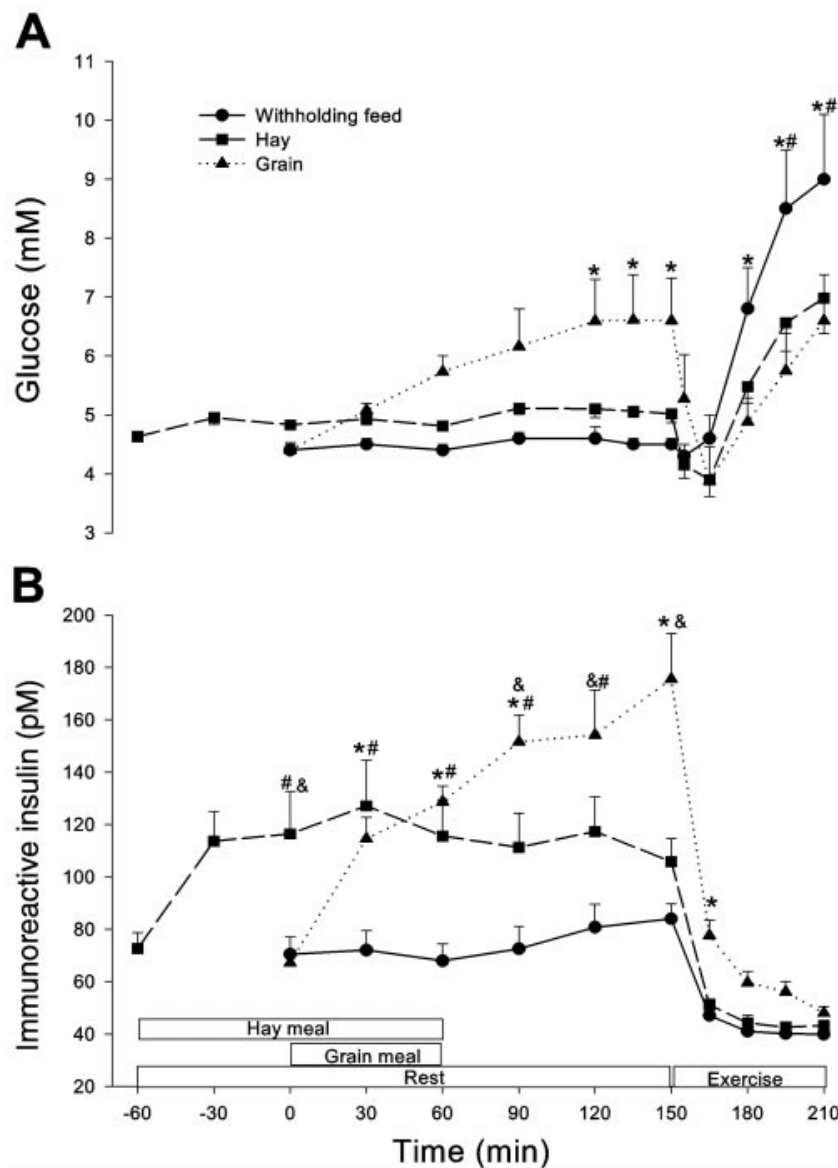

Fig. 1. Plasma glucose $(A)$ and serum immunoreactive insulin $(B)$ at rest and during $60 \mathrm{~min}$ of exercise at $50 \pm 0.7 \%$ of maximal oxygen uptake after horses had feed withheld (withholding feed), were fed a hay meal (hay), or were fed an approximately isocaloric grain meal (grain) 90 min before exercise. Values are means $\pm \mathrm{SE}$ for 6 horses. *Grain meal significantly different from withholding feed, $P<0.05$. "Hay meal significantly different from withholding feed, $P<0.05$. ${ }^{\&}$ Grain meal significantly different from hay meal, $P<0.05$.

one-quarter of the daily energy requirements, glucose concentration steadily increased from $4.4 \pm 0.1 \mathrm{mM}$ before the meal to $6.6 \pm 0.7 \mathrm{mM}$ at $150 \mathrm{~min}$ (Fig. $1 A$ ). Plasma glucose concentration remained unchanged in horses fed the hay meal and in which the feed was withheld. During exercise in feed-withholding trials, plasma glucose concentration increased steadily to reach a peak of $9.0 \pm 0.1 \mathrm{mM}$, whereas in grain trials, plasma glucose concentration decreased from preexercise values during the first $15 \mathrm{~min}$ of exercise and were subsequently similar to values in hay trials. Plasma glucose concentrations were higher $(P<0.05)$ in feedwithholding trials than in grain or hay meal trials during the second half of the exercise trial.

Serum insulin. Feeding type before exercise significantly altered serum IRI concentrations before and during exercise. Allowing horses to eat a hay meal induced an insulinemic response in which IRI increased over $60 \%(127.1 \pm 17.5 \mathrm{pM}$ at $30 \mathrm{~min})$ from IRI concentrations before feeding $(72.7 \pm 6.1 \mathrm{pM}$ at -60 min; $P<0.001$; Fig. $1 B$ ). Serum IRI concentrations steadily increased after a grain meal from $67.2 \pm 4.9$
$\mathrm{pM}$ at $0 \mathrm{~min}$ to reach a peak of $175.6 \pm 17.4 \mathrm{pM} 150$ min after the meal was offered $(P<0.001)$. During exercise, serum IRI decreased in all trials but in grain meal trials remained elevated above values in feedwithholding trials for the first 15 min of exercise $(P<$ $0.05)$. No differences in serum IRI concentration were found among trials between 30 and 60 min of exercise.

NEFA and glycerol. Plasma glycerol concentrations were affected by feeding type during exercise but not before exercise. Plasma glycerol concentrations during the second half of exercise were significantly lower in grain trials than in hay or feed-withholding trials. Plasma glycerol concentration increased steadily during exercise in all trials from $\sim 0.1 \pm 0.0 \mathrm{mM}$ to reach a peak of $1.22 \pm 0.1,1.13 \pm 0.1$, and $0.96 \pm 0.1 \mathrm{mM}$ at 60 min of exercise for feed-withholding, hay, and grain trials, respectively $(P<0.001 ; 150$ vs. $210 \mathrm{~min}$; Fig. $2 A)$. Feeding type before exercise altered plasma NEFA concentrations before and during exercise. During the 120 -min period in which horses were allowed to eat hay, plasma NEFA steadily decreased from $0.90 \pm 0.2$

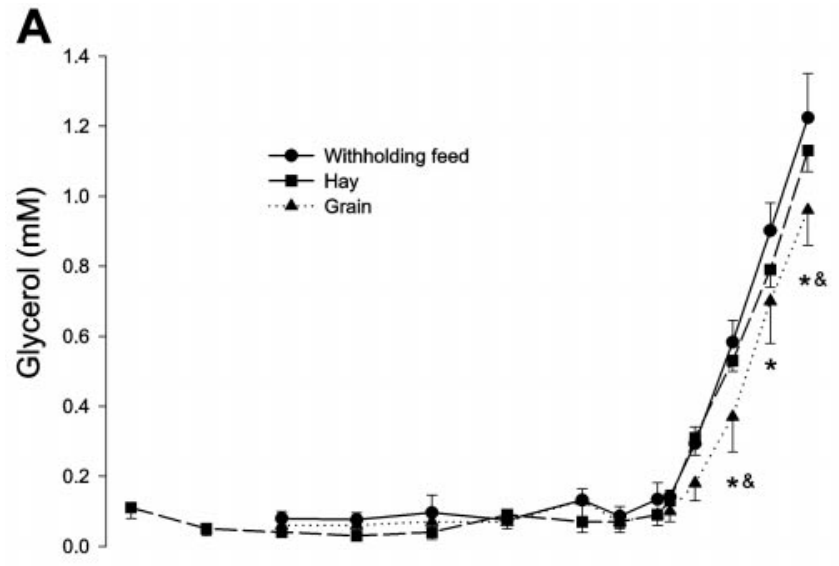

B

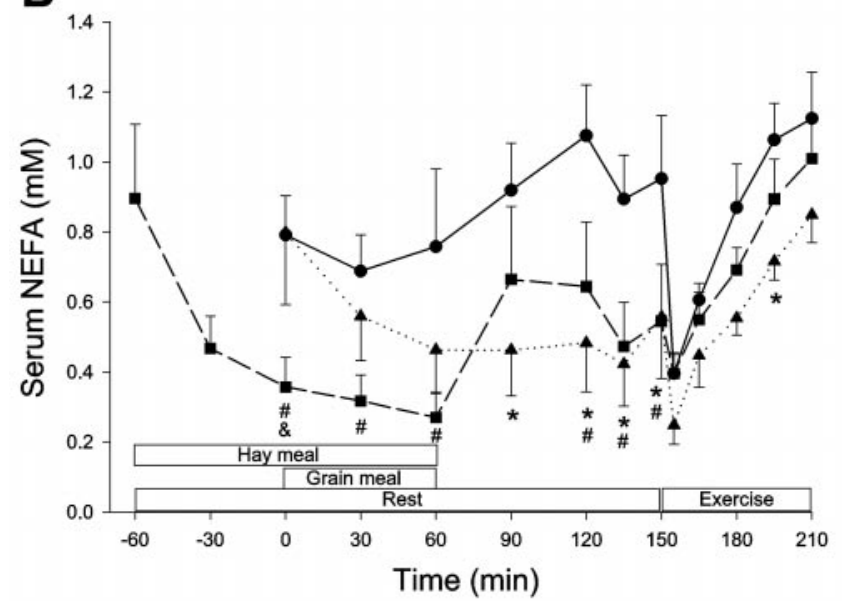

Fig. 2. Plasma glycerol $(A)$ and nonesterified fatty acids (NEFA; $B)$ at rest and during $60 \mathrm{~min}$ of exercise at $50 \pm 0.7 \%$ of maximal oxygen uptake after withholding feed, feeding hay, or feeding grain 90 min before exercise. Values are means \pm SE for 6 horses. *Grain meal significantly different from withholding feed, $P<0.05$. "Hay meal significantly different from withholding feed, $P<0.05$. ${ }^{\&}$ Grain meal significantly different from hay meal, $P<0.05$. 
$\mathrm{mM}$ before the hay meal to $0.27 \pm 0.1 \mathrm{mM}$ at $60 \mathrm{~min}$ $(P<0.001)$. NEFA concentration gradually decreased after both hay and grain meal trials, whereas in feedwithholding trials, it initially remained unchanged and gradually increased (Fig. 2B). Plasma NEFA concentration decreased sharply at commencement of exercise in feed-withholding trials $(0.95 \pm 0.2 \mathrm{mM}$ immediately before exercise and $0.40 \pm 0.1 \mathrm{mM}$ at $5 \mathrm{~min}$ of exercise; $P=0.003$; Fig. $2 B$ ). Plasma NEFA concentrations during exercise were significantly lower in the grain trial than in the feed-withholding and hay trials $(P<0.05)$.

Respiratory gas exchange and whole body substrate oxidation. Feeding type before exercise altered RER and the whole body rates of $\mathrm{CHO}_{\text {ox }}$ and lipid oxidation during exercise. There was a small but significant $(P<$ 0.001) increase in $\dot{\mathrm{V}}_{2}$ during the $60 \mathrm{~min}$ of treadmill exercise, and $\dot{\mathrm{V}}_{2}$ was similar among the three trials (Table 2). RER decreased significantly in all three trials over the 60 min of exercise $(P<0.001)$, and at 60 min of exercise grain trials had a significantly higher RER compared with hay trials $(0.89 \pm 0.01$ and $0.84 \pm$ 0.01 , grain vs. hay; $P=0.021$ ). TEE steadily increased over time from $126.1 \pm 3.3,127.8 \pm 5.6$, and $129.1 \pm$ $4.1 \mathrm{kcal} / \mathrm{min}$ at $5 \mathrm{~min}$ to $143.1 \pm 2.9,138.3 \pm 2.6$, and $140.2 \pm 2.6 \mathrm{kcal} / \mathrm{min}$ at $60 \mathrm{~min}$ for feed-withholding, hay, and grain trials, respectively $(P<0.001$; Table 2$)$. Total $\mathrm{CHO}_{\text {ox }}$ decreased during exercise in feed-withholding and hay trials but remained stable in grain trials. Total $\mathrm{CHO}_{\text {ox }}$ was higher in grain than in hay trials at $60 \mathrm{~min}$ of exercise $(327 \pm 26$ vs. $239 \pm 26$ $\mu \mathrm{mol} \cdot \mathrm{kg}^{-1} \cdot \mathrm{min}^{-1}$, grain vs. hay; $P=0.023$ ). Conversely, fat oxidation was suppressed in grain trials compared with feed-withholding and hay trials, and at $60 \mathrm{~min}$ the rate of fat oxidation was significantly lower in grain trials $\left(49 \pm 4 \mu \mathrm{mol} \cdot \mathrm{kg}^{-1} \cdot \mathrm{min}^{-1}\right.$ ) compared with hay trials $\left(72 \pm 8 \mu \mathrm{mol} \cdot \mathrm{kg}^{-1} \cdot \mathrm{min}^{-1} ; P=0.016\right)$.

Glucose kinetics. Feeding type before exercise altered plasma glucose isotopic enrichment and glucose $R_{d}$ before and during exercise, and it altered glucose $R_{a}$ before exercise as well as glucose MCR during exercise. Before exercise, plasma isotopic enrichment (Fig. 3) was lower in grain trials than in feed-withholding and hay trials $(P<0.001)$. During the first 5 min of exercise, plasma isotopic enrichment increased in all trials; however, in grain trials, plasma isotopic enrichment

Table 2. Rate of oxygen consumption, respiratory exchange ratio, rate of carbohydrate and lipid oxidation, calculated muscle glycogen (and lactate) oxidation, and rate of glucose disappearance during $60 \mathrm{~min}$ of exercise at $50 \pm 0.7 \%$ of $\dot{\mathrm{V}}_{2} \max$

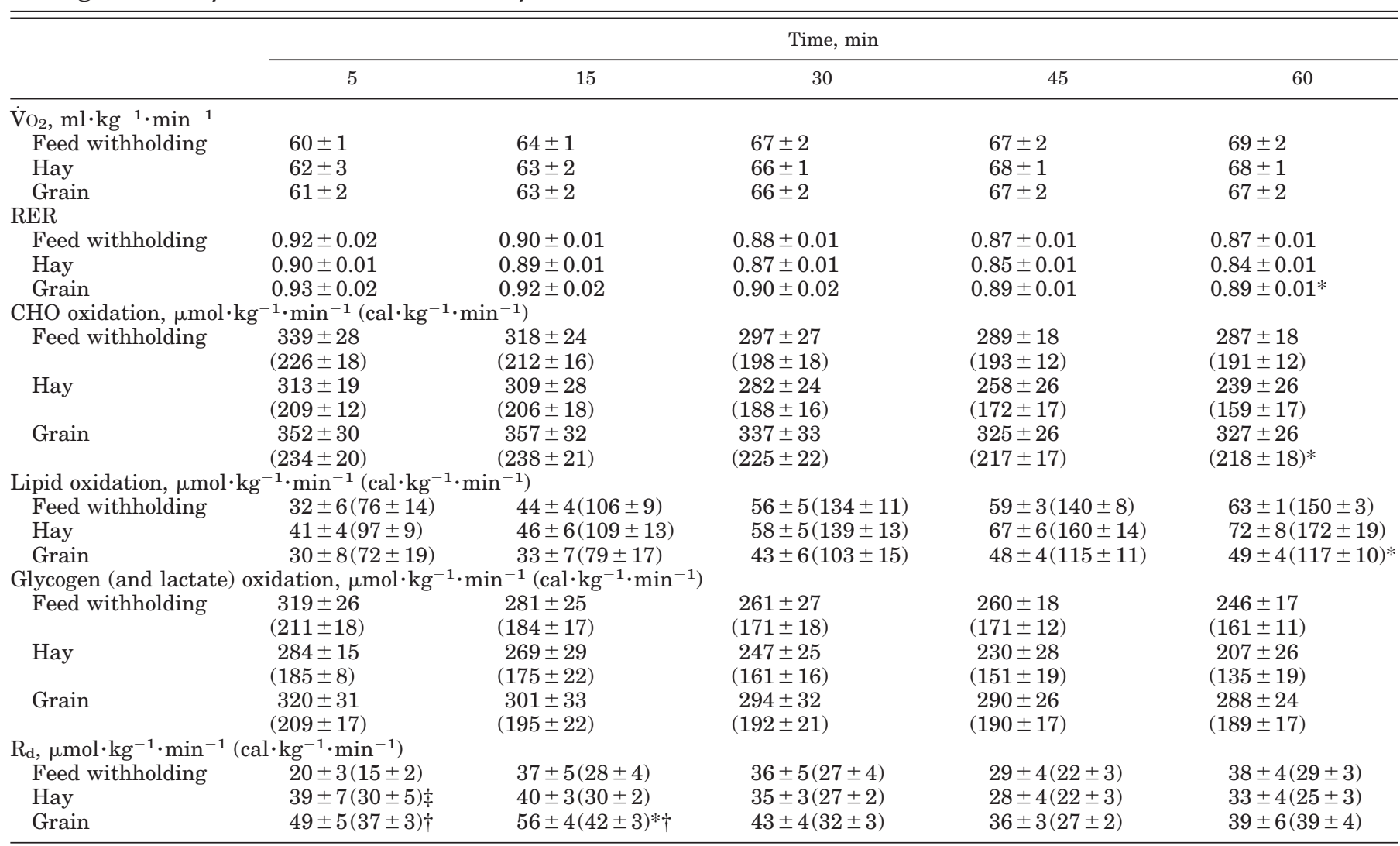

Values are means \pm SE for 6 horses. Horses had food withheld (food withholding), were fed a hay meal (hay), or were fed a grain meal (grain) 90 min before exercise. Rates of oxygen consumption $\left(\mathrm{V}_{2}\right)$ and respiratory exchange ratio (RER) were calculated from 5-min average values. Rates of carbohydrate (CHO) and fat oxidation were calculated from respiratory gas exchange data, averaged over 5 min. Muscle glycogen (plus lactate) oxidation was estimated from the difference between total carbohydrate oxidation and rate of glucose disappearance. Values in parentheses are the relative caloric contributions to energy expenditure from oxidation of CHO, lipid, muscle glycogen (and lactate), and blood-borne glucose. $* P<0.05$, grain vs. hay. $\dagger P<0.05$, grain vs. feed withholding. $\ddagger P<0.05$, hay vs. feed withholding. 
values remained stable, whereas in feed-withholding and hay trials, plasma isotopic enrichment steadily decreased despite the threefold increase in tracer infusion rate.

At rest, the mean glucose $R_{\mathrm{a}}$ (Fig. $4 A$ ) and $R_{\mathrm{d}}$ (Fig. $4 B$ ) during the grain trials were both $\sim 70 \%$ greater than during feed-withholding and hay trials (both $\mathrm{R}_{\mathrm{a}}$ and $\left.\mathrm{R}_{\mathrm{d}} ; P<0.005\right)$. Glucose $\mathrm{R}_{\mathrm{a}}$ increased steadily in all trials from $7.9 \pm 0.7,8.1 \pm 0.6$, and $13.6 \pm 1.6$ $\mu \mathrm{mol} \cdot \mathrm{kg}^{-1} \cdot \mathrm{min}^{-1}$ to reach a peak of $60 \pm 6,52 \pm 4$, and $53 \pm 7 \mu \mathrm{mol} \cdot \mathrm{kg}^{-1} \cdot \mathrm{min}^{-1}$ for feed-withholding, hay, and grain trials, respectively, at $30 \mathrm{~min}$ of exercise $(P<0.001)$. During the second half of the exercise trial, $R_{\mathrm{a}}$ remained stable or decreased slightly in all trials.

During exercise, there was a significant trial effect $(P=0.007)$ for glucose $R_{\mathrm{d}}$. Whereas glucose $R_{\mathrm{d}}$ increased with the onset of exercise in all trials, the increase was much larger in grain trials (Fig. $4 B$ ). In feed-withholding and hay trials, glucose $R_{d}$ increased from $7.9 \pm 0.7$ and $8.1 \pm 0.6 \mu \mathrm{mol} \cdot \mathrm{kg}^{-1} \cdot \mathrm{min}^{-1}$ before exercise to reach a peak of $37 \pm 5$ and $40 \pm 3$ $\mu \mathrm{mol} \cdot \mathrm{kg}^{-1} \cdot \mathrm{min}^{-1}$, respectively, at $15 \mathrm{~min}$ of exercise $(P<0.001)$ and remained stable or decreased slightly during the rest of the exercise period. In grain trials, glucose $\mathrm{R}_{\mathrm{d}}$, increased sharply from $13.6 \pm 1.6$ $\mu \mathrm{mol} \cdot \mathrm{kg}^{-1} \cdot \mathrm{min}^{-1}$ before exercise to reach a peak of $56 \pm 4 \mu \mathrm{mol} \cdot \mathrm{kg}^{-1} \cdot \mathrm{min}^{-1}$ at $15 \mathrm{~min}$ of exercise $(P<$ 0.001 ), and it steadily decreased during the rest of the exercise. Glucose MCR demonstrated a similar pattern (Fig. 5). During exercise MCR was $\sim 50-100 \%$ higher in grain trials than in feed-withholding trials $(P<0.05$ at 5,15 , and $30 \mathrm{~min}$ ), whereas only at 5 min was MCR higher in hay trials compared with feed-withholding trials $(P<0.05)$.

Muscle glycogen. Preexercise muscle glycogen concentration was similar among the three trials (Fig. 6). Net muscle glycogen utilization during exercise was

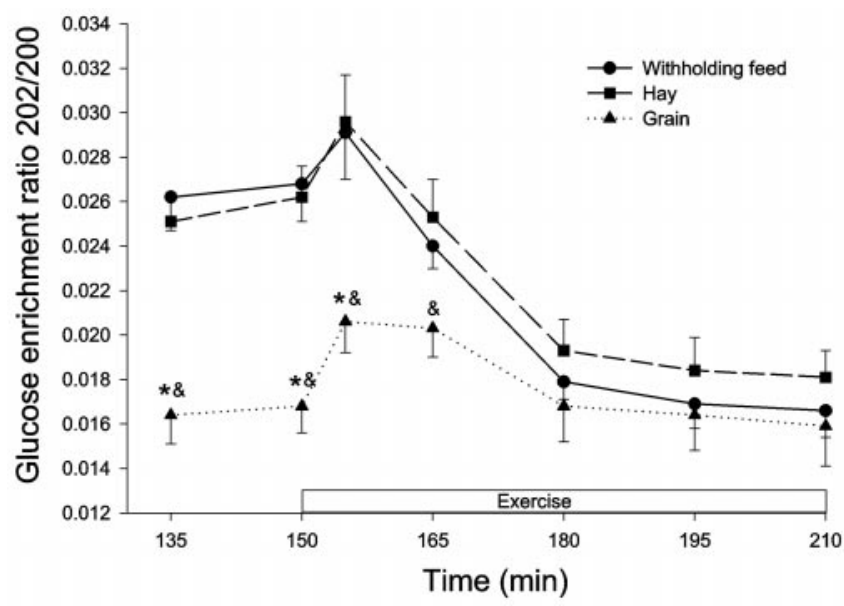

Fig. 3. Plasma isotopic enrichment at rest and during $60 \mathrm{~min}$ of exercise at $50 \pm 0.7 \%$ of maximal oxygen uptake after withholding feed, feeding hay, or feeding grain $90 \mathrm{~min}$ before exercise. Values are means \pm SE for 6 horses. 202/200, Mass-to-charge ratio of labeled and unlabeled ions, respectively. *Grain meal significantly different from withholding feed, $P<0.05 .{ }^{\&}$ Grain meal significantly different from hay meal, $P<0.05$.
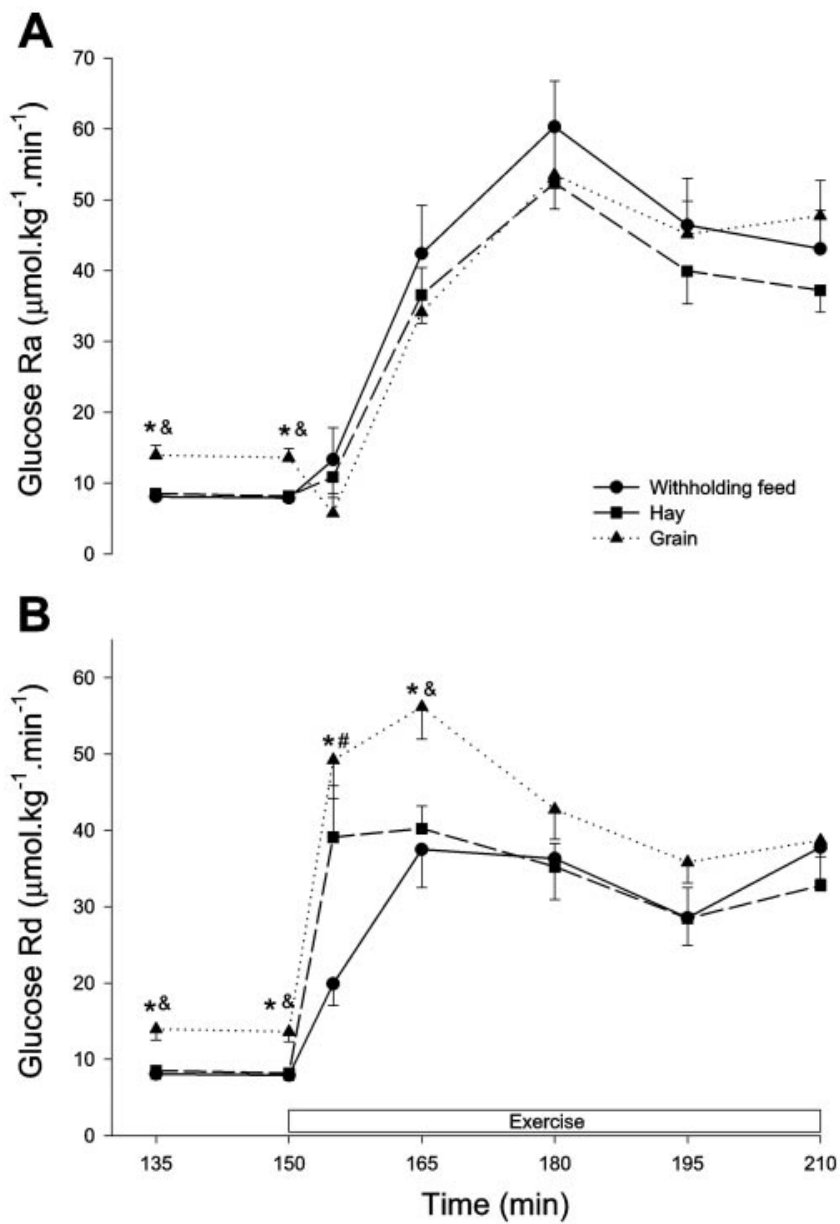

Fig. 4. Glucose rate of appearance $\left(\mathrm{R}_{\mathrm{a}} ; A\right)$ and disappearance $\left(\mathrm{R}_{\mathrm{d}}\right.$; $B$ ) at rest and during $60 \mathrm{~min}$ of exercise at $50 \pm 0.7 \%$ of maximal oxygen uptake after withholding feed, feeding hay, or feeding grain 90 min before exercise. Values are means \pm SE for 6 horses. *Grain meal significantly different from withholding feed, $P<0.05$. \# Hay meal significantly different from withholding feed, $P<0.05$.

${ }^{\&}$ Grain meal significantly different from hay meal, $P<0.05$.

similar $(P=0.6)$ among the three trials $(47 \pm 9,44 \pm$ 11 , and $35 \pm 8 \mathrm{mmol} / \mathrm{kg}$ wet muscle in feed-withholding, hay, and grain trials, respectively). Postexercise muscle glycogen concentration was lower compared with preexercise samples in all trials $(P<0.001)$. The calculated rates of muscle glycogen oxidation (total $\mathrm{CHO}_{\text {ox }}-$ glucose $\mathrm{R}_{\mathrm{d}}$ ) during exercise were not affected by meal type (Table 2 ).

Hematocrit, plasma total protein, and lactate. Feeding type before exercise altered hematocrit and plasma total protein concentration before exercise but did not affect plasma lactate concentration. Hematocrit was significantly increased by $5 \mathrm{~min}$ of exercise and remained elevated throughout exercise in all trials (35$37 \%$ immediately before exercise and $49-50 \%$ at $5 \mathrm{~min}$ of exercise; $P<0.001$; Table 3). During the resting period in hay meal trials, hematocrit was higher than in grain meal and feed-withholding trials (feeding $\times$ time, $P<0.059$ ). Plasma total protein concentration followed a pattern similar to that for hematocrit. Plasma total protein concentration increased signifi- 


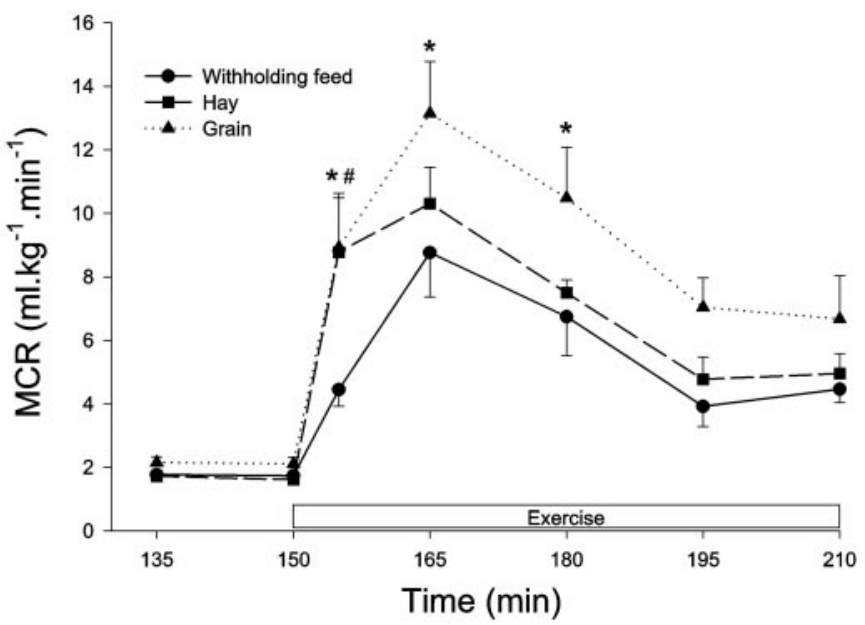

Fig. 5. Glucose metabolic clearance rate (MCR) at rest and during 60 min of exercise at $50 \pm 0.7 \%$ of maximal oxygen uptake after withholding feed, feeding hay, or feeding grain 90 min before exercise. Values are means \pm SE for 6 horses. * Grain meal significantly different from withholding feed, $P<0.05$. "Hay meal significantly different from withholding feed, $P<0.05$.

cantly by 5 min of exercise and remained elevated throughout exercise in all trials $(6.8-7.0 \mathrm{~g} / \mathrm{dl}$ immediately before exercise and $7.3-7.6 \mathrm{~g} / \mathrm{dl}$ at $5 \mathrm{~min}$ of exercise; $P<0.001$; Table 3 ). During the period immediately after hay meal feeding, plasma total protein concentration increased from $7.1 \pm 0.1$ to $7.5 \pm 0.1 \mathrm{~g} / \mathrm{dl}$, whereas in grain meal and feed-withholding trials, plasma total protein concentration remained essentially unchanged $(6.9 \pm 0.1$ and $7.1 \pm 0.1 \mathrm{~g} / \mathrm{dl}$, respectively, for grain and feed withholding; feeding $\times$ time, $P<0.001$ ). Plasma lactate concentration increased steadily in all trials to reach a peak of $3.9 \pm 0.4,4.3 \pm$ 0.6 , and $4.2 \pm 0.5 \mathrm{mM}$ at $60 \mathrm{~min}$ of exercise for feedwithholding, hay, and grain trials, respectively $(P<$ $0.001,150$ vs. 210 min; Table 2).

Overall pattern of substrate utilization. Feeding type before exercise altered the overall pattern of substrate utilization during exercise. Figure 7 depicts the estimated relative caloric contribution from oxidation of muscle glycogen and lactate (other $\mathrm{CHO}_{\text {ox }}$ ), fat, and blood glucose during the first and second half of exercise. The total rate of energy expenditure was similar among the three trials $(325 \pm 7,322 \pm 5,324 \pm 5$ $\mathrm{cal} \cdot \mathrm{kg}^{-1} \cdot \mathrm{min}^{-1}$ for feed-withholding, hay, and grain trials, respectively). During the first half of exercise, no differences were detected among the three trials in the relative contributions to energy expenditure from fat and muscle glycogen oxidation. The contribution of blood glucose during the first half of exercise was $\sim 85$ and $\sim 35 \%$ higher in grain compared with feed-withholding and hay trials, respectively $(P<0.05)$, and $\sim 40 \%$ higher in hay compared with feed-withholding trials $(P<0.05)$. During the second half of exercise, contribution of blood glucose was similar among all trials. The contribution of muscle glycogen decreased significantly during the second half of exercise; however, the decrease in the contribution of muscle glycogen was attenuated in grain trials, and a tendency was observed in grain trials to have a higher muscle glycogen contribution compared with hay trials $(P=0.11)$. In hay trials, during the second half of exercise, the relative caloric contribution of fat oxidation was higher compared with grain trials $(48 \pm 4$ and $34 \pm 4 \% ; P<$ 0.05 , hay vs. grain).

\section{DISCUSSION}

The present study examined the effects of a HGM (grain trial), an approximately isocaloric LGM (hay trial), or feed-withholding before exercise on $\mathrm{CHO}$ and lipid metabolism in horses during moderate-intensity exercise. The main findings were 1) a $50 \%$ increase in whole body $R_{d}$ occurs during the first 30 min of moderate-intensity exercise after feeding a corn meal before exercise, compared with exercise after withholding feed for $18 \mathrm{~h}$; 2) feeding a hay or grain meal, irrespective of the glycemic index of a meal fed before exercise, decreases plasma glucose concentration during exercise, compared with exercise after withholding feed; 3) augmentation of $\mathrm{CHO}_{\text {ox }}$ and attenuation of lipid oxidation occurred during exercise in trials preceded by corn feeding; and 4) feeding status before exercise does not affect net muscle glycogen utilization.

As expected, feeding a HGM before exercise resulted in marked hyperglycemia (Fig. $1 A$ ) and hyperinsulinemia (Fig. $1 B$ ) before the exercise bout. These results are consistent with findings of previous studies of the effect of feeding of different grains and/or roughages on plasma metabolite and hormone concentrations in horses $(29,30,34,43)$. Stull and Rodiek (42) showed that a corn meal that provides $25 \%$ of the energy requirements induces a $\sim 50 \%$ increase in plasma glucose concentration that peaks between 2 and $3 \mathrm{~h}$ after eating and a sixfold increase in serum IRI concentration that peaks $2 \mathrm{~h}$ after eating. However, in the same study, an isocaloric amount of alfalfa hay did not induce an increase in plasma glucose and serum IRI concentrations. This is in contrast to our findings, in which hay feeding did not result in an increase in

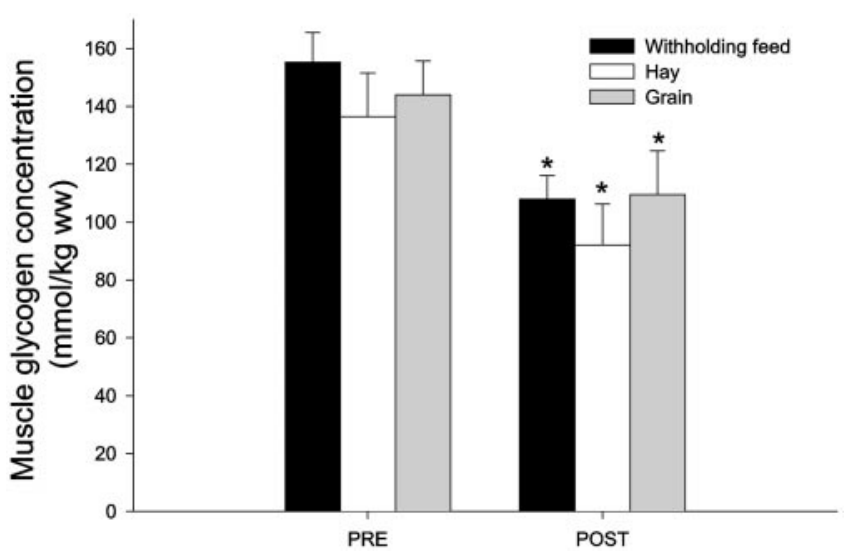

Fig. 6. Muscle glycogen concentrations before (Pre) and after (Post) $60 \mathrm{~min}$ of exercise at $50 \pm 0.7 \%$ of maximal oxygen uptake after withholding feed, feeding hay, or feeding grain 90 min before exercise. Values are means \pm SE for 6 horses. ww, Wet weight. * Significant difference compared with preexercise values, $P<0.05$. 
Table 3. Hematocrit and plasma total protein and lactate concentrations before and during 60 min of exercise at $50 \pm 0.7 \%$ of $\dot{V}_{2} \max$

\begin{tabular}{|c|c|c|c|c|c|c|c|c|}
\hline & \multicolumn{8}{|c|}{ Time, min } \\
\hline & \multicolumn{3}{|c|}{ Rest } & \multicolumn{5}{|c|}{ Exercise } \\
\hline \multicolumn{9}{|l|}{ Hematocrit, \% } \\
\hline Feed withholding & $38 \pm 2$ & $35 \pm 1$ & $35 \pm 2$ & $49 \pm 1$ & $50 \pm 1$ & $49 \pm 1$ & $48 \pm 1$ & $49 \pm 1$ \\
\hline Hay & $39 \pm 1$ & $39 \pm 1 \div$ & $37 \pm 1$ & $49 \pm 1$ & $50 \pm 1$ & $49 \pm 1$ & $49 \pm 1$ & $49 \pm 1$ \\
\hline Grain & $36 \pm 1$ & $34 \pm 2 *$ & $35 \pm 1$ & $50 \pm 1$ & $49 \pm 1$ & $48 \pm 1$ & $49 \pm 1$ & $50 \pm 1$ \\
\hline Hay & $7.5 \pm 0.2 \ddagger$ & $7.3 \pm 0.2$ & $6.9 \pm 0.1$ & $7.3 \pm 0.1$ & $7.4 \pm 0.1$ & $7.3 \pm 0.2$ & $7.5 \pm 0.1$ & $7.6 \pm 0.2$ \\
\hline Grain & $6.9 \pm 0.1^{*}$ & $6.9 \pm 0.1^{*}$ & $6.8 \pm 0.1$ & $7.4 \pm 0.2$ & $7.2 \pm 0.2$ & $7.1 \pm 0.2$ & $7.3 \pm 0.1$ & $7.4 \pm 0.2$ \\
\hline \multicolumn{9}{|l|}{ Lactate, mM } \\
\hline Feed withholding & $0.4 \pm 0.0$ & $0.4 \pm 0.0$ & $0.5 \pm 0.0$ & $0.7 \pm 0.1$ & $1.6 \pm 0.1 \dagger$ & $2.9 \pm 0.3 \dagger$ & $3.9 \pm 0.4 \dagger$ & $3.9 \pm 0.4 \dagger$ \\
\hline Hay & $0.6 \pm 0.0$ & $0.6 \pm 0.0$ & $0.6 \pm 0.1$ & $1.0 \pm 0.1$ & $2.0 \pm 0.2 \dagger$ & $3.6 \pm 0.6 \dagger$ & $4.2 \pm 0.7 \dagger$ & $4.3 \pm 0.6 \dagger$ \\
\hline Grain & $0.6 \pm 0.0$ & $0.6 \pm 0.1$ & $0.6 \pm 0.0$ & $0.9 \pm 0.1$ & $1.5 \pm 0.2 \dagger$ & $3.1 \pm 0.4 \dagger$ & $4.0 \pm 0.5 \dagger$ & $4.2 \pm 0.5 \dagger$ \\
\hline
\end{tabular}

Values are means \pm SE for 6 horses. Values during exercise are from 155 to 210 min. $\dot{\mathrm{V}}_{2 \text { max }}$, maximal $\dot{\mathrm{V}}_{2}$. $* P<0.05$, grain vs. hay. $\ddagger P<$ 0.05 , hay vs. feed withholding; $\dagger P<0.05,165-210$ min vs. 150 min. Hematocrit and plasma total protein from 155 to 210 min are higher than $150 \min (P<0.001)$ in all trials.

plasma glucose but hay consumption resulted in a $60 \%$ increase in serum IRI concentration. The meals fed in this study achieved our aim of offering meals of different glycemic indexes to horses before exercise.

In this study, the increase in plasma glucose concentration induced by corn feeding was accompanied by increments in glucose $R_{\mathrm{a}}$ and $R_{\mathrm{d}}$. Glucose $R_{\mathrm{a}}$ was similar in horses that had food withheld and that were fed hay and was similar to previous estimations by intravenous $\left[2-{ }^{3} \mathrm{H}\right]$ glucose infusion of the total glucose production in two ponies fed hay $(9.8$ $\mu \mathrm{mol} \cdot \mathrm{kg}^{-1} \cdot \mathrm{min}^{-1}$ ) (39). During exercise, glucose $R_{\mathrm{d}}$ was significantly higher in trials preceded by ingestion of a grain meal compared with trials preceded by a hay meal or withholding feed. Similarly, in hu- mans, ingestion of a HGM (mashed potatoes) or glucose solution before moderate-intensity exercise results in higher glucose $R_{\mathrm{a}}$ and $\mathrm{R}_{\mathrm{d}}$ before and during exercise, compared with LGM (muesli), placebo, or fasting $(8,22,27)$. However, preexercise glucose ingestion markedly decreases hepatic glucose production during exercise, and the increase in glucose $R_{a}$ reflects ongoing intestinal uptake of glucose (27). In the present study, we did not measure the contribution of gut-derived $R_{\mathrm{a}}$ (intestinal absorption of glucose) to the total $R_{a}$. Nonetheless, it is likely that continued absorption of glucose from the gastrointestinal tract contributed to the higher glucose $R_{a}$ before exercise in horses fed a grain meal. During the first half of exercise in horses fed grain, because the

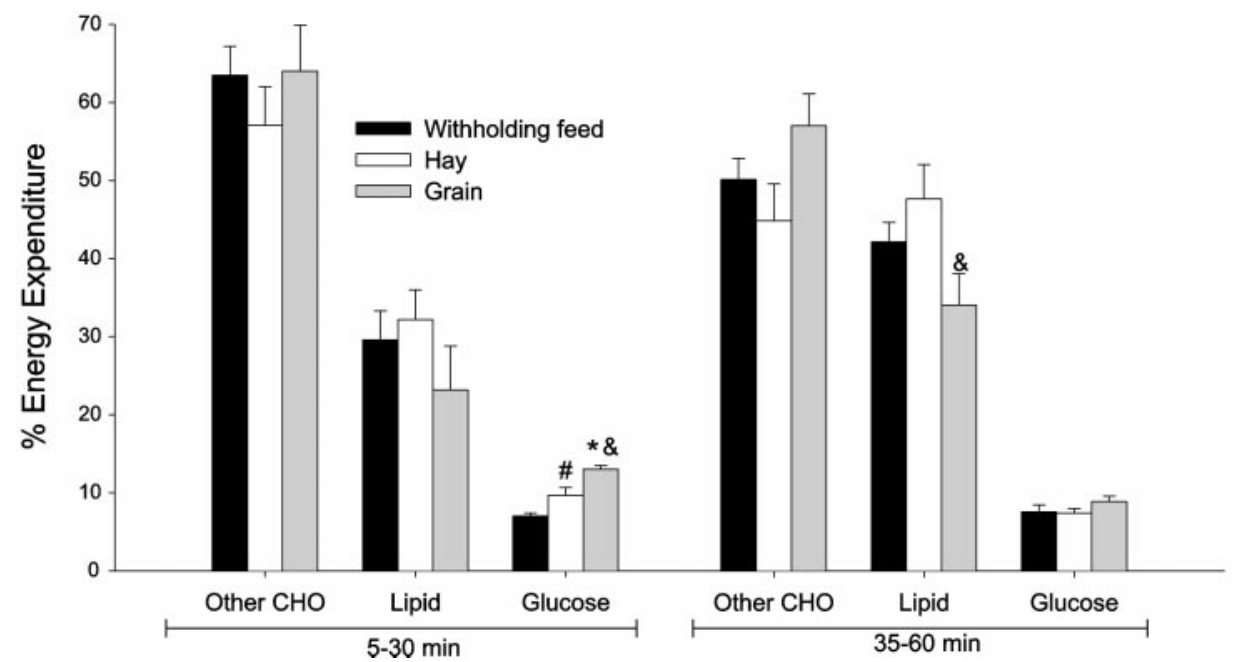

Fig. 7. Relative caloric contributions from oxidation of other carbohydrate (CHO; muscle glycogen and lactate), lipid, and blood glucose during the 5- to 30-min and 35- to 60 -min periods of exercise after withholding feed, feeding hay, or feeding grain 90 min before exercise. Values are means \pm SE for 6 horses. *Grain meal significantly different from withholding feed, $P<0.05$. "Hay meal significantly different from withholding feed, $P<0.05$. \& Grain meal significantly different from hay meal, $P<0.05$. For all trials, the percent energy expenditure of each substrate oxidation is significantly different at $5-30 \mathrm{~min}$ vs. $35-60 \mathrm{~min}(P<0.05)$, except glucose utilization in trials after withholding feed. 
increase in glucose $R_{d}$ was not accompanied by a similar increase in glucose $R_{a}$, plasma glucose concentration decreased sharply. However, plasma glucose concentrations during exercise in horses fed grain were not different from in horses fed hay before exercise. This is in contrast to previous studies performed in horses $(34,43)$ in which horses fed corn before exercise had lower plasma glucose concentrations during exercise compared with those of horses fed alfalfa hay before exercise.

In horses that had feed withheld, blood glucose concentrations steadily increased during the exercise bout and were higher than in horses fed before exercise. These findings are consistent with previous studies in horses $(24,25,29,30,43)$ but not in humans $(8,23,37$, $38,40,44)$. Endurance-trained human athletes cycling at a higher relative exercise intensity $\left(85 \% \dot{\mathrm{V}}_{2}\right.$ max $)$ but a similar absolute exercise intensity $(58 \mathrm{ml}$ $\mathrm{O}_{2} \cdot \mathrm{kg}^{-1} \cdot \mathrm{min}^{-1}$ ) had similar responses to exercise than the horses in this study (35). Human athletes exercising at an intensity that elicits a similar $\mathrm{V}_{2}$ as for the horses in this study had also a steady increase in blood glucose concentrations during the exercise bout $(\sim 3.9$ $\mathrm{mM}$ before and $\sim 8.2 \mathrm{mM}$ during exercise) and had similar glucose $R_{d}$ before and during exercise $(\sim 10$ $\mu \mathrm{mol} \cdot \mathrm{kg}^{-1} \cdot \mathrm{min}^{-1}$ before and $\sim 50 \mu \mathrm{mol} \cdot \mathrm{kg}^{-1} \cdot \mathrm{min}^{-1}$ during exercise) and similar relative and absolute contributions from different substrates to energy expenditure during exercise $\left(\sim 180 \mathrm{cal} \cdot \mathrm{kg}^{-1} \cdot \mathrm{min}^{-1}\right.$ from muscle glycogen oxidation, $\sim 80 \mathrm{cal} \cdot \mathrm{kg}^{-1} \cdot \mathrm{min}^{-1}$ from muscle triglyceride and plasma NEFA oxidation, and $\sim 40 \mathrm{cal} \cdot \mathrm{kg}^{-1} \cdot \mathrm{min}^{-1}$ from plasma glucose oxidation) (35). These differences between human subjects and horses may be associated with the greater aerobic capacity of horses; in other words, when horses exercise at the same work intensity relative to $\dot{\mathrm{V}}_{2}$ max as human athletes, the $\dot{\mathrm{V}}_{2}$ and the workload are much greater in horses than in human athletes. (46) Therefore, when some metabolic responses to exercise are compared, it may be more meaningful to compare human athletes and horses when they are performing exercise tasks that elicit similar $\dot{\mathrm{V}}_{\mathrm{O}_{2}}$.

Previous studies in horses have led to recommendations of feeding before exercise based on changes in substrate and hormone concentrations in plasma or serum $(29,30)$. Because of the exercise-induced decrease in plasma glucose concentration and reduced NEFA availability in horses fed grain before exercise, it has been recommended not to feed a grain meal before exercise $(29,30)$. In humans, ingestion of a HGM before and/or during exercise has resulted in enhanced $(13,23,37,38)$, decreased (44), or unchanged submaximal exercise performance $(8,9,18,40,47)$. In horses, the effect of $\mathrm{CHO}$ ingestion on performance during moderate-intensity exercise has not been determined. Therefore, recommendations on interval and type of feeding before exercise can only be offered based on the metabolic responses induced by the interval of feeding and the composition of the meal. Determination of plasma or serum concentration of metabolites and substrates has been the sole means for providing recom- mendations of dietary manipulations in horses before exercise. These studies have provided little insight into the influence of feeding status before exercise on substrate supply and utilization during exercise. The combination of estimation of whole body $\mathrm{CHO}_{\text {ox }}$ and fat oxidation rates (by indirect calorimetry measurements) and estimation of rates of appearance and disappearance of metabolites in plasma (by measurement of infused metabolites labeled with stable isotopes) is the only means to determine the contribution of extramuscular and intramuscular substrates to energy production. To the best of our knowledge, the present study is the first one that estimates the contribution of extramuscular and intramuscular substrates to energy production in horses fed different meals or denied access to food before exercise.

Ingestion of corn before exercise resulted in a significant decrease in plasma glycerol concentration during exercise (Fig. 2A) and plasma NEFA concentration before and during exercise (Fig. 2B). Lower plasma NEFA concentrations in grain trials also may have contributed to the higher rate of glucose utilization in this trial compared with hay or feed withholding trials. In humans, preexercise CHO ingestion inhibits lipolysis during moderate-intensity exercise and suppresses the increase in plasma NEFA concentration $(6,20)$. Similarly, in horses, preexercise ingestion of corn attenuates the increase in fatty acid concentration during exercise $(25,42)$.

Feeding corn before exercise resulted in a greater relative contribution to energy expenditure from bloodborne glucose during the initial half of a 60 -min moderate-intensity exercise event, compared with withholding feed, and it resulted in greater $\mathrm{CHO}_{\text {ox }}$ and lower lipid oxidation during the second half of the exercise bout, compared with hay feeding before exercise (Fig. 7). Similarly to the results in our present study, increased glucose availability during $60 \mathrm{~min}$ of running at $55 \% \quad \mathrm{VO}_{2}$ max by preexercise intragastric administration of glucose $[2 \mathrm{~g} / \mathrm{kg}, 10 \mathrm{kcal} / \mathrm{kg} \mathrm{DE}(41.6$ $\mathrm{kJ} / \mathrm{kg} \mathrm{DE})]$ to horses resulted in enhanced $\mathrm{CHO}_{\text {ox }}$ and utilization of blood-borne glucose during moderate-intensity exercise but did not alter muscle glycogen utilization (15). In studies performed in human subjects, ingestion of glucose or HGMs before exercise results in enhanced $\mathrm{CHO}_{\text {ox }}$ and utilization of blood-borne glucose, and the rate of glycogenolysis may be enhanced (18) or unchanged $(9,17,22,23)$. The same controversy is apparent in regard to the effect of increased glucose availability on muscle glycogenolysis in studies performed in horses. Lawrence et al. (24) reported that increased glucose availability by ingestion of a HGM before exercise enhances muscle glycogenolysis in exercising horses, compared with feed withholding $[\sim 46$ vs. $18 \mathrm{mmol} / \mathrm{kg}$ wet wt in $\sim 15 \mathrm{~min}$ exercise test of 1.6 $\mathrm{km}$ at $6 \mathrm{~m} / \mathrm{s}, 0.8 \mathrm{~km}$ at $1.9 \mathrm{~m} / \mathrm{s}$ (treadmill grade changed to $2 \%$ ), 0.4-km speed-up period, and a final 1.6 $\mathrm{km}$ at $11 \mathrm{~m} / \mathrm{s}]$. This is in contrast to the findings of this study (Fig. 6), previous studies performed in our laboratory $(14,15)$, and studies by others $(7)$, in which increased glucose availability by preexercise ingestion 
of grain, intragastric glucose administration, or CHOrich diet, respectively, did not alter muscle glycogenolysis during exercise. However, in our study, a nonsignificant reduction of muscle glycogenolysis of $\sim 25 \%$ was noted when horses were fed grain before exercise compared with feed withholding.

TEE during $60 \mathrm{~min}$ of exercise was $\sim 19.3 \mathrm{kcal} / \mathrm{kg}$ $(\sim 80.4 \mathrm{~kJ} / \mathrm{kg})$, which is $\sim 33.8 \mathrm{kcal} / \mathrm{kg} \mathrm{DE}(\sim 141 \mathrm{~kJ} / \mathrm{kg}$ DE) assuming an efficiency of utilization of DE of $57 \%$ (31). When this is translated into National Research Council nutritional requirements (28) and the maintenance energy requirements are added $[\sim 33.1 \mathrm{kcal} / \mathrm{kg}$ $\mathrm{DE}(\sim 138 \mathrm{KJ} / \mathrm{kg} \mathrm{DE})]$, there is an average total daily energy requirement of $\sim 66.9 \mathrm{kcal} / \mathrm{kg} \mathrm{DE}(\sim 278.8 \mathrm{~kJ} / \mathrm{kg}$ $\mathrm{DE}$ ), an increase over maintenance of $\sim 102 \%$. Rose et al. (36) reported similar increases in daily energy requirement $(\sim 112 \%)$ for horses exercised at $50 \% \dot{\mathrm{V}}_{2}$ max for 75 min, and Pagan and Hintz (31) reported lower increases in daily energy requirement over maintenance $(\sim 67 \%)$ for $450-\mathrm{kg}$ horses exercised for $2 \mathrm{~h}$ on a flat surface at $4.2 \mathrm{~m} / \mathrm{s}$ by a $75-\mathrm{kg}$ rider. These estimates of the increase in energy requirements for exercising horses may be useful in the future to develop more accurate guidelines of the nutritional requirements of these animals.

In summary, this study has demonstrated that feeding of a HGM before exercise augments $\mathrm{CHO}_{\text {ox }}$ and utilization of blood-borne glucose in horses during moderate-intensity exercise but does not alter muscle glycogen usage. Conversely, feeding of an isocaloric LGM with roughage before exercise, compared with a HGM, augments lipid oxidation in horses during moderate-intensity exercise but does not alter muscle glycogen usage. These findings support that feeding a HGM $2 \mathrm{~h}$ before exercise might be indicated in exercise bouts of moderate intensity in which $\mathrm{CHO}_{\mathrm{ox}}$ is responsible for supplying more than half of the energy requirement for energy transduction during exercise.

The authors thankfully acknowledge Jeong-Su Kim at The Ohio State University for technical assistance with analysis of blood samples. The technical assistance of Leia Hill is also gratefully acknowledged. Thanks are also due to the School of Physical Activity and Educational Services, College of Education, The Ohio State University, for assistance with analysis of blood and muscle samples.

This study was supported by grants from the Equine Research Funds at The Ohio State University and Purina Mills, St. Louis, MO.

\section{REFERENCES}

1. Coggan AR and Coyle EF. Reversal of fatigue during prolonged exercise by carbohydrate infusion or ingestion. $J$ Appl Physiol 63: 2388-2395, 1987.

2. Coggan AR and Coyle EF. Effect of carbohydrate feedings during high-intensity exercise. J Appl Physiol 65: 1703-1709, 1988.

3. Coggan AR, Kohrt WM, Spina RJ, Bier DM, and Holloszy JO. Endurance training decreases plasma glucose turnover and oxidation during moderate-intensity exercise in men. $J$ Appl Physiol 68: 990-996, 1990.

4. Coyle EF, Coggan AR, Hemmert MK, and Ivy JL. Muscle glycogen utilization during prolonged strenuous exercise when fed carbohydrate. J Appl Physiol 61: 165-172, 1986.

5. Coyle EF, Hagberg BF, Hurley BF, Martin WH, Ehsani AA, and Holloszy JO. Carbohydrate feeding during prolonged strenuous exercise can delay fatigue. J Appl Physiol 55: 230235, 1983.

6. Coyle EF, Jeukendrup AE, Wagenmakers AJM, and Saris WHM. Fatty acid oxidation is directly regulated by carbohydrate metabolism during exercise. Am J Physiol Endocrinol Metab 273: E268-E275, 1997.

7. Essén-Gustavsson B, Blomstrand E, Karlström K, Lindholm A, and Persson SGB. Influence of diet on substrate metabolism during exercise. In: Equine Exercise Physiology 3, edited by Persson SGB, Lindholm A, and Jeffcott LB. Davis, CA: ICEEP Publications, 1991, p. 288-298.

8. Febbraio MA, Keenan J, Angus DJ, Campbell SE, and Garnham AP. Preexercise carbohydrate ingestion, glucose kinetics, and muscle glycogen use: effect of the glycemic index. J Appl Physiol 89: 1845-1851, 2000.

9. Febbraio MA and Stewart KL. CHO feeding before prolonged exercise: effect of glycemic index on muscle glycogenolysis and exercise performance. J Appl Physiol 81: 1115-1120, 1996.

10. Fedak MA, Rome L, and Seeherman HJ. One-step $\mathrm{N}_{2}$-dilution technique for calibrating open-circuit $\dot{\mathrm{V}}_{2}$ measuring systems. J Appl Physiol 51: 772-776, 1981.

11. Ferranini E. The theoretical bases of indirect calorimetry: a review. Metabolism 37: 287-301, 1988.

12. Frayn KN. Calculation of substrate oxidation rates in vivo from gaseous exchange. J Appl Physiol 55: 628-634, 1983.

13. Gleeson M, Maughan RJ, and Greenhaff PL. Comparison of the effects of pre-exercise feeding of glucose, glycerol and placebo on endurance and fuel homeostasis in man. Eur J Appl Physiol 55: 645-653, 1986.

14. Geor RJ, Hinchcliff KW, McCutcheon LJ, and Sams RA. Epinephrine inhibits exogenous glucose utilization in exercising horses. J Appl Physiol 88: 1777-1790, 2000.

15. Geor RJ, Hinchcliff KW, and Sams RA. Glucose infusion attenuates endogenous glucose production and enhances glucose use of horses during exercise. J Appl Physiol 88: 1765-1776, 2000.

16. Goodpaster BH, Costill DL, Fink WJ, Trappe TA, Jozsi AC, Starling RD, and Trappe SW. The effects of pre-exercise starch digestion on endurance performance. Int J Sports Med 17: 366-372, 1996.

17. Hargreaves M, Costill DL, Fink WJ, and King DS. Effect of pre-exercise carbohydrate feedings on endurance cycling performance. Med Sci Sports Exerc 19: 33-36, 1987.

18. Hargreaves M, Costill DL, Katz A, and Fink WJ. Effect of fructose ingestion on muscle glycogen usage during exercise. Med Sci Sports Exerc 17: 360-363, 1985.

19. Hinchcliff KW, McKeever KH, Muir WW, and Sams RA. Effect of furosemide and weight carriage on energetic responses of horses to incremental exertion. Am J Vet Res 54: 1500-1504, 1993.

20. Horowitz JF, Mora-Rodriguez R, Byerley LO, and Coyle EF. Lipolytic suppression following carbohydrate ingestion limits fat oxidation during exercise. Am J Physiol Endocrinol Metab 273: E768-E775, 1997.

21. Jacobs KA and Sherman WM. The efficacy of carbohydrate supplementation and chronic high-carbohydrate diets for improving endurance performance. Int J Sport Nutr 9: 92-115, 1999.

22. Jeukendrup AE, Raben A, Gijsen A, Stegen JHC, Brouns F, Saris WHM, and Wagenmakers AJM. Glucose kinetics during prolonged exercise in highly trained human subjects: effect of glucose ingestion. J Physiol (Lond) 515: 579-589, 1999.

23. Kirwan JP, O'Gorman D, and Evans WJ. A moderate glycemic meal before endurance exercise can enhance performance. J Appl Physiol 84: 53-59, 1998.

24. Lawrence LM, Hintz HF, Soderholm LV, Williams J, and Roberts AM. Effect of time of feeding on metabolic response to exercise. Equine Vet J Suppl 18: 393-395, 1995.

25. Lawrence L, Soderholm LV, Roberts A, Williams J, and Hintz H. Feeding status affects glucose metabolism in exercising horses. J Nutr 123: 2152-2157, 1993.

26. Lindholm A and Piehl K. Fiber composition, enzyme activity and concentrations of metabolites and electrolytes in muscles of standardbred horses. Acta Vet Scand 15: 287-309, 1974. 
27. Marmy-Conus N, Fabris S, Proietto J, and Hargraves M. Preexercise glucose ingestion and glucose kinetics during exercise. J Appl Physiol 81: 853-857, 1996.

28. National Research Council. Nutrient Requirements of Horses (5th rev. ed.). Washington, DC: Natl. Acad. Press, 1998.

29. Pagan JD and Harris PA. The effects of timing and amount of forage and grain on exercise response in Thoroughbred horses. Equine Vet J Suppl 30: 451-457, 1999.

30. Pagan JD, Burger I, and Jackson SG. The influence of time of feeding on exercise response in Thoroughbreds fed a fat supplemented or high carbohydrate diet. In: Proceedings of the 9th Equine Nutrition and Physiology Symposium. East Lansing, MI: The Equine Nutrition and Physiology Society and Michigan State University, 1995, p. 92-93.

31. Pagan JD and Hintz HF. Equine energetics. II. Energy expenditure in horses during submaximal exercise. J Anim Sci 63: 822-830, 1986.

32. Passonneau JR and Lauderdale VR. A comparison of three methods of glycogen measurement in tissues. Anal Biochem 60: 405-412, 1974.

33. Reimers TJ, Cowan RG, McCann JP, and Ross MW. Validation of rapid solid-phase radioimmunoassay for canine, bovine, and equine insulin. Am J Vet Res 43: 1274-1278, 1982.

34. Rodiek A, Bonvicin S, Stull C, and Arana M. Glycemic and endocrine responses to corn or alfalfa fed prior to exercise. In: Equine Exercise Physiology 3, edited by Persson SGB, Lindholm A, and Jeffcott LB. Davis, CA: ICEEP Publications, 1991, p. $323-330$

35. Romijn JA, Coyle EF, Sidossis LS, Gastaldelli A, Horowitz JF, Endert E, and Wolfe RR. Regulation of endogenous fat and carbohydrate metabolism in relation to exercise intensity and duration. Am J Physiol Endocrinol Metab 265: E380-E391, 1993.

36. Rose RJ, Knight PK, and Bryden WL. Energy use and cardiorespiratory responses to prolonged submaximal exercise. In: Equine Exercise Physiology 3, edited by Persson SGB, Lindholm A, and Jeffcott LB. Davis, CA: ICEEP Publications, 1991, p. $281-287$.
37. Sherman WM, Brodowicz G, Wright DA, Allen WK, Simonsen J, and Dernbach A. Effects of $4 \mathrm{~h}$ preexercise carbohydrate feedings on cycling performance. Med Sci Sports Exerc 21: 598604, 1989.

38. Sherman WM, Peden MC, and Wright DA. Carbohydrate feedings $1 \mathrm{~h}$ before exercise improves cycling performance. Am $J$ Clin Nutr 54: 866-870, 1991.

39. Simmons HA and Ford EJH. Gluconeogenesis from propionate produced in the colon of the horse. Br Vet $J$ 147: 340-345, 1991.

40. Sparks MJ, Selig SS, and Febbraio MA. Pre-exercise carbohydrate ingestion: effect of the glycemic index on endurance exercise performance. Med Sci Sports Exerc 30: 844-849, 1998.

41. Steele R. Influences of glucose loading and of injected insulin on hepatic glucose output. Ann NY Acad Sci 82: 420-430, 1959.

42. Stull CL and Rodiek AV. Responses of blood glucose, insulin, and cortisol concentrations to common equine diets. J Nutr 118: 206-213, 1988.

43. Stull C and Rodiek A. Effects of postprandial interval and feed type on substrate availability during exercise. Equine Vet $J$ 18: 362-366, 1995.

44. Thomas DE, Brotherood JR, and Brand JC. Carbohydrate feeding before exercise: effect of glycemic index. Int $J$ Sports Med 12: 180-186, 1991

45. Tsintzas OK, Williams C, Wilson W, and Burrin J. Influence of carbohydrate supplementation early in exercise on endurance running capacity. Med Sci Sports Exerc 28: 1373-1379, 1996.

46. Wagner PD. Determinants of $\mathrm{VO}_{2}$ max: man vs. horse. J Equine Vet Sci 15: 398-404, 1995.

47. Wee SL, Williams C, Gray S, and Horabin J. Influence of high and low glycemic index meals on endurance running capacity. Med Sci Sports Exerc 31: 393-399, 1999.

48. Wolfe RR. Radioactive and Stable Isotope Tracers in Biomedicine. New York: Wiley-Liss, 1992.

49. Wright DA, Sherman WM, and Dernbach AR. Carbohydrate feedings before, during, or in combination improve cycling endurance performance. J Appl Physiol 71: 1082-1088, 1991. 